\title{
Corrigendum
}

\section{Corrigendum to "Existence of Solutions for a Coupled System of Second and Fourth Order Elliptic Equations"}

\author{
Fanglei Wang \\ College of Science, Hohai University, Nanjing 210098, China \\ Correspondence should be addressed to Fanglei Wang; leizil123@163.com \\ Received 6 November 2016; Accepted 21 November 2016; Published 11 May 2017 \\ Copyright (C) 2017 Fanglei Wang. This is an open access article distributed under the Creative Commons Attribution License, which \\ permits unrestricted use, distribution, and reproduction in any medium, provided the original work is properly cited.
}

In the article titled "Existence of Solutions for a Coupled System of Second and Fourth Order Elliptic Equations" [1], there was an error in Acknowledgments, which should be corrected as follows.

This research is supported by the Natural Science Foundation of Jiangsu Province, Grant (no. BK20130825).

\section{References}

[1] F. Wang, "Existence of solutions for a coupled system of second and fourth order elliptic equations," Abstract and Applied Analysis, vol. 2014, Article ID 680919, 4 pages, 2014. 


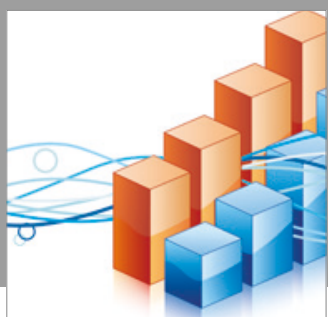

Advances in

Operations Research

vatersals

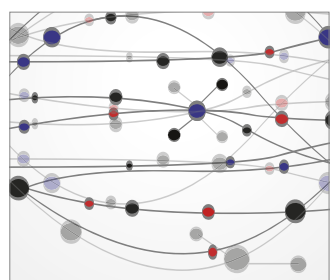

\section{The Scientific} World Journal
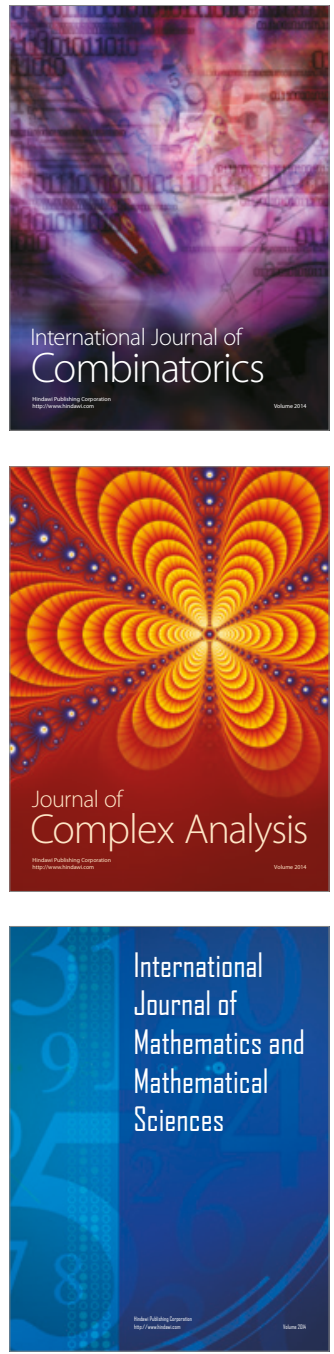
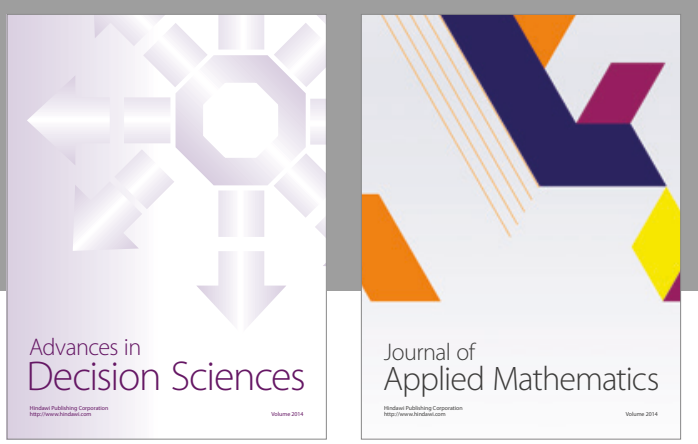

Algebra

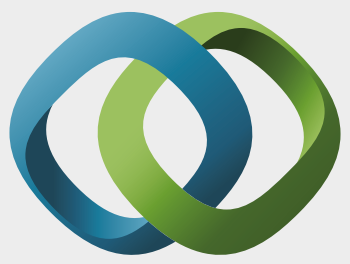

\section{Hindawi}

Submit your manuscripts at

https://www.hindawi.com
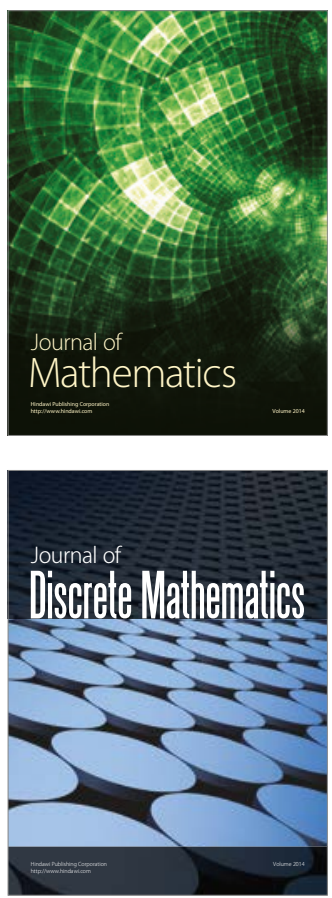

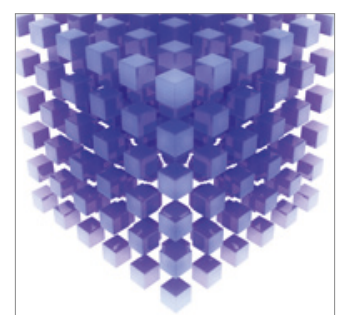

Mathematical Problems in Engineering
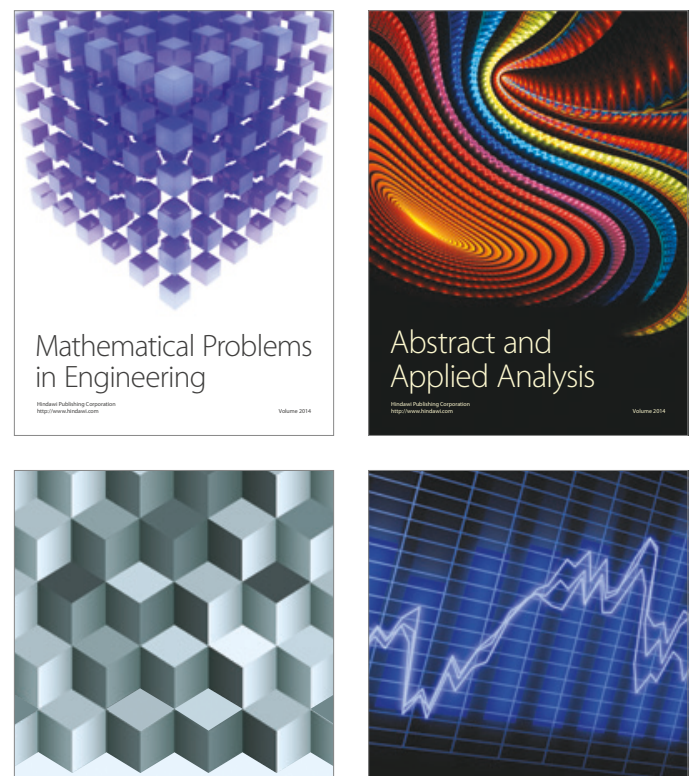

Journal of

Function Spaces

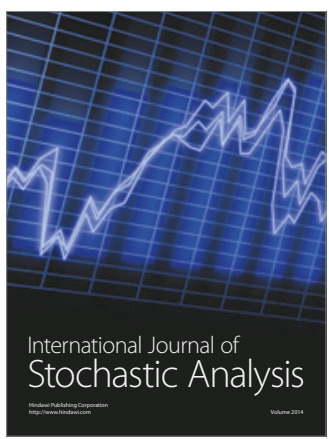

Probability and Statistics
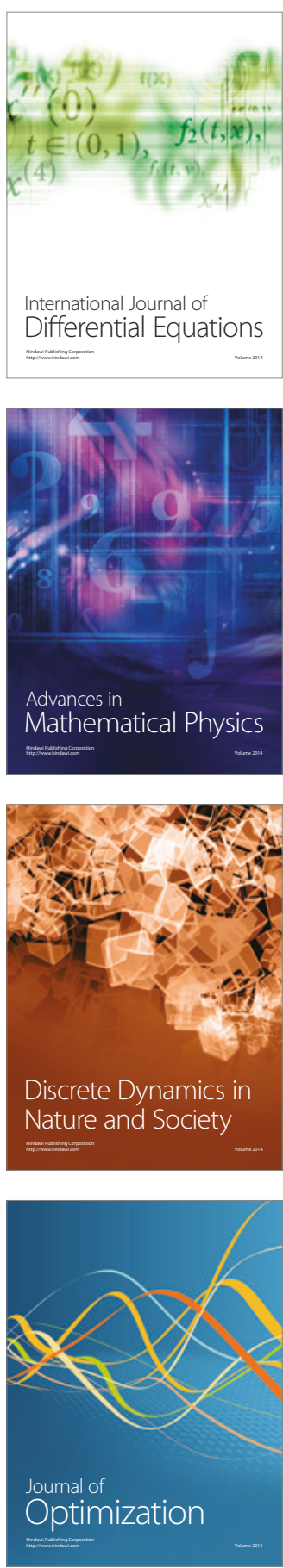